\title{
Understanding Qualitative and Community Indicators of Poverty for National Health Insurance Scheme Exemptions in Ghana
}

\author{
Dr Da Costa Aboagye \\ Health Promotion and Public Health, College of Nursing, Midwifery and Healthcare, \\ University of West London, UK \\ Email: DaCosta.Aboagye@uwl.ac.uk
}

Telephone: 00442082094067

Professor Jane South

School of Community Studies, Leeds Beckett University, Leeds, UK

Email: J.South@leedsbeckett.ac.uk

Telephone: +441138124406

Professor Hafiz T.A. Khan (Corresponding Author)

The Graduate School, University of West London, St Mary's Road, London, UK

Email: hafiz.khan@uwl.ac.uk

Telephone: 00442082312953

\begin{abstract}
The exemptions of the National Health Insurance Scheme (NHIS) for poor people in Ghana have not been sufficiently explored. Using a qualitative approach that involved gathering and analysing viewpoints from the community, this paper investigates the factors that are used to determine NHIS exemptions in Ghana. Focus group discussions (FGDs) and interviews of key informants (KIs) were conducted during the period (August 2015 to August 2016) within the Ashanti and Greater Accra regions in Ghana. Nine FGDs were conducted in nine different communities with 72 respondents. Nine KIs, including local and national policy-makers, civil servants and local community members were also interviewed. A sampling method was adopted to capture a range of understandings of community indicators of poverty for NHIS exemptions. Community perceptions of the indicators of poverty included interconnected
\end{abstract}


themes of income, employment, education, assets, and social marginalisation. The findings highlight contextual and community descriptions associated with exemptions, of which poverty is a predictor, and discovered that to identify the indigent for exemptions based only on income and quantitative measures is not enough. The results are significant for a number of reasons including poor fit with official measures and the neglect of lay perspectives. For practice implications, our findings show that communities should be principal stakeholders for describing the disadvantaged groups that require exemptions.

Keywords: Exemptions, NHIS, Ghana, Community, poverty.

\section{Introduction}

Poverty is multifaceted, predominantly connected to inadequate income, but it has other dimensions such as social aspects, human rights, equity, emotions and dignity (1). Typical measurements of equity and poverty may not take into account all features associated with poverty within an overall population if they are one-dimensional and dependent only on income poverty $(1,2,3)$. Income poverty is generally defined when a family's income fails to meet a country's established threshold and is adjusted for the number of persons in a family (4). Such a measurement may fail to consider a multifaceted poverty description $(2,5)$. As Sen (6) noted, the lives of people can be battered and weakened for various reasons, and the main duty therefore is to recognise that various forms of deprivation can greatly add to the effects of poverty.

A precise assessment of these deprivations is needed in order to evaluate the moral questions of poverty and inequities and their characteristics (6). According to Barimah and Mensah (7), in circumstances where inequities and poverty prevail, it is more cost-effective to invest in the poor for their self-advancement than in the rich, as the latter are susceptible to absorb more capital than can be justified economically. If a multi-dimensional view of poverty is taken, then this has implications not only for poverty measurement but also for the construction and implementation of policies that are 'pro-poor'. So there is a need to have a clear understanding about poverty in society in order for NHIS exemptions to be appropriately administered. The main aim of this paper is to investigate factors beyond poverty for determining whether or not a person would qualify for NHIS exemptions. 
Ghana is one of the low- middle income countries in Africa with high growth in exports from gold ( $\$ 4.5$ billion), cocoa ( $\$ 1.9$ billion), and oil (\$2.6 billion) (8). An assessment of income disparity as determined by a minimum income change compared to the national wage change in Ghana, increased to $1.8 \%$ from 2001 to 2008 but then decreased after 2008 from $8.4 \%$ to $4.0 \%$ in 2009 with the worst decline of negative 5\% experienced during 2012 to $2015(9,10)$. However, Ghana still uses consumption, expenditure and income poverty line methods to determine poverty levels widely (11).

The Government of Ghana established the NHIS in 2003 as a type of national health insurance with the goal of providing equitable access and financial coverage for basic healthcare services to Ghanaians $(12,13)$. The NHIS policy was part of a national framework in Ghana aiming to curtail out-of-pocket payment at the point of care and to guarantee fairness of access, chiefly for poor people $(12,13)$. Policy implementation started from 2004 to substitute the previous user fees system.

In 2012, a new NHIS Act (852) was introduced with the same aim of curtailing out-of-pocket payments and to build on the successes of the previous NHIS Act of $2003(12,13)$. The 2012 NHIS Act required funds to be taken from employed individuals (all workers) or households by means of direct deduction of a $2.5 \%$ national health insurance levy (NHIL) from the payroll; by a $2.5 \%$ value added tax included in the price of goods and services and a fixed insurance premium for informal sector workers (3). As of 2012, the National Health Insurance Fund (NHIF) derived more than $70 \%$ of its financial entries from the NHIL including premium payments of $4.5 \%$ and Social Security and National Insurance Trust (SSNIT) contributions of $17.4 \%$. Additional funding sources for the NHIF include financial gifts, voluntary donations, grants, interest amassed from shares/investments and money assigned by parliament (13:3).

Legislation exempts various groups of people from paying the premium, such as pensioners of SSNIT, adults above age 70, core poor (indigents) and children under age of 18 years (12, 3). The NHIS Legislative Instrument (LI 1809) stated that:

" a person shall be identified as an indigent and exempted from premium payments under four main criteria - that is, (a) does not have a fixed place of residence according to standards determined by the scheme, $(b)$ does not have any identifiable consistent support from another person (c) the person is unemployed and has no 
visible source of income and $(d)$ does not live with a person who is employed and who has a fixed place of residence"(14, p 21).

Other global studies, including research from Ghana, have used quantitative methods to help analyse data in connection with premium exemptions for the poor $(2,16)$. Such studies normally compare evaluations of the effectiveness and efficiency of participatory capital, proxy means testing, geographic targeting and means testing in societies with various socio economic factors $(3,16,17)$. The geographic targeting, for example, catalogues specific urban or rural areas into impoverished groups according to cumulative indicators of poverty and equity $(3,18,19)$. Participatory capital classification evaluates individuals or households as poor based on a prescribed equity model of the society $(2,18)$. Proxy means testing weighs people and households in terms of expenditure and income thresholds (15). In light of the preponderance of quantitative methods in this area of research, this study uses a qualitative approach involving a community viewpoint to investigate qualification for NHIS exemptions.

\section{Materials and Methods}

The findings presented here are part of a broader study that examined the NHIS in Ghana from policy, equity, community and healthcare perspectives (19). The study adopted an interpretative stance, which recognised that the social world is created through people's meanings and motivations and that knowledge is constructed by people's engagement with that world (20). The study focus was on the NHIS as a pro-poor policy and the establishment of the NHIF as a route to subsidise the premium of informal sector workers and to pay the premium for vulnerable groups including indigents referred to in this paper as the 'poorest' or 'core poor'. To capture perspectives on how the NHIS worked in communities, in-depth focus group discussions (FGDs) were conducted with members of purposely selected local communities, plus key informant interviews with a sample of civil servants, local and national policy-makers from the NHIS and government. The study was based in two regions in Ghana (Ashanti and Greater Accra), which were purposely selected. Fieldwork took place between August 2015 and August 2016.

A qualitative approach was considered necessary for this study as opinions and views from local populations can be largely ignored in research projects (21) and yet they can provide rich data. The problems associated with outside investigators conducting research in any 
country is well recognised (22). The researcher in this study did not live in Ghana and there were some practical and ethical challenges to overcome. Entry into research sites was negotiated through the local authorities (chiefs, assemblymen, and opinion leaders), health research links and the Ministry of Health after the objectives of the research had been presented and ethical clearance given by the Ghana Health Service.

After these permissions had been granted, purposive sampling was used to gain a sample with 'maximum variation' (23) in terms of the experiences of people within the selected local communities. This variation included area differences in demography, economy and geography. Distinct geographical areas were first identified based on evidence of inequality in terms of: income levels (based on UNICEF data on (4) income inequality in Ghana); transportation to health centres; and whether areas were described as affluent or poor by local gatekeepers. Primary gatekeepers and local authorities in each of the communities were then asked to confirm the selection. Respondents were recruited via invitation letters explaining the aims and scope of the study. All participants provided written consent prior to data collection. Throughout the course of the study, it was important to create and maintain a sense of trust with the local community and those who had agreed to be research participants. Part of this involved emphasising that the study was independent from the Ghana Health Service and the Ministry of Health.

Nine communities took part in the study; five in the Ashanti region and four communities in the Greater Accra region. Based on evidence of economic inequalities, there were five poor communities and four affluent communities. In total, 81 people took part in the study, with 46 men (42 participating in FGDs and 4 participating in key informant interviews) and 35 women (30 participating in FGDs and 5 participating in key informant interviews). Nine focus group discussions were held lasting between one and a half hours on average and involving a total of 72 community members. Nine key informants were interviewed, including regional policy-makers and officials of Ghana Health Service and Ministry of Health, and interviews lasted between one and two hours. Participants freely expressed themselves during interviews and focus groups. . A single researcher collected all the data. Figure 1 gives a summary of the sample composition. 
Smple Orerrier/Characteristics

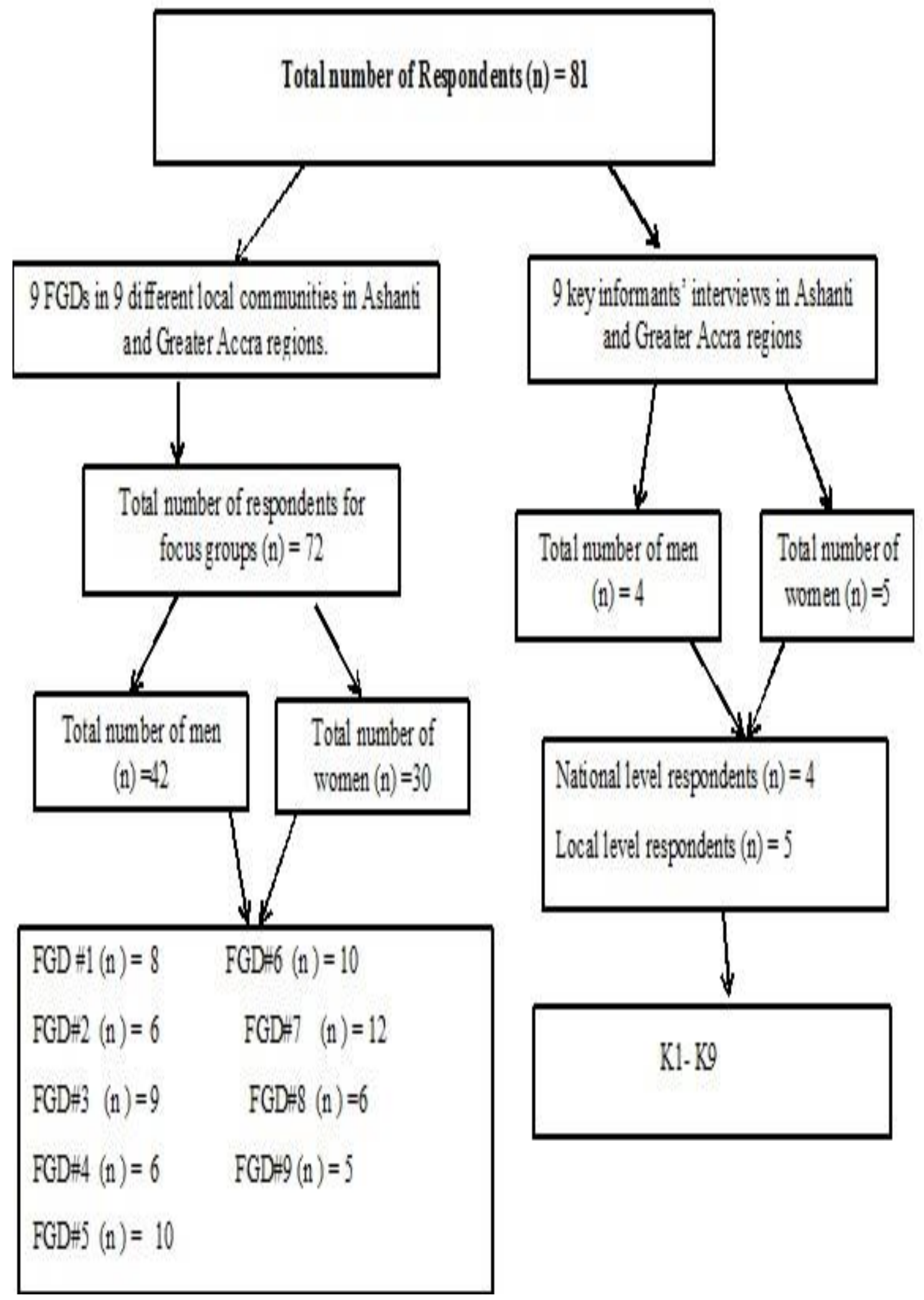




\section{Ethical considerations}

The study received ethical and written approval from the author's institution. A preorientation for all respondents was done to encourage everyone to contribute in discussions. Only adults aged 18 years of age and over participated in FGDs. All participants were promised confidentiality and anonymity, and everyone provided written or oral consent. A tape recorder was used to document both the key informant interviews and the FGDs. Brief notes were also taken during the interview, written down and organized at the end of the interview. One key informant did not give permission for audio-recording and summary notes were taken instead.

\section{Data analysis}

The qualitative data from FGDs and key informant interviews were analysed together. The use of thematic networks, as promoted by Attride-Stirling, (24) was employed as a systematic technique for organising and synthesising the data. Further details of how this analytical approach was applied to the data can be found elsewhere (19). The first stage was organising initial codes into basic themes. Themes frequently arose from the data itself (inductive) or from prior understandings of the study topic (25). The distinct stages of analysis make explicit the processes of generating interpretation and theory from text and transcripts.

Though an investigator's decision is critical to shaping thematic groupings, Bernard et al. (26) and Ryan and Bernard (27) suggested helpful schemes for arriving at a theme. Repetition of main issues in the raw data, illustratively, is one of the simplest forms of theme classification. After basic themes were classified, they were arranged to make organising themes and then the principal global theme was created, which concisely summarises features of the data. The final product was a web-like matrix. NVivo 7 software was used to aid the analysis. In reporting the findings, the FGDs were labelled with numbers from 1 to 9 as (FGD \# 1 to FGD\# 9) and key informant interviews (K1 to K9) respectively. 


\section{Results}

Salient themes from the data relating to poverty and NHIS include income, employment, education, assets, social marginalisation and each of these themes is discussed in the following sections.

\section{Income}

Discussion about the many determinants of poverty was a strong theme in the focus groups and key informant interviews as respondents shared their understandings of the link between poverty and NHIS exemptions. Participants in all the communities taking part cited lack of income as being related to poverty and extreme poverty. They described poverty as things being very tight money-wise, for example, and a struggle to buy food either on a transitory or long-term chronic basis. The descriptions also included a person who is poor sometimes borrowing money from other people and repaying in the future with abject or extreme poverty referring to those experiencing a constant financial struggle on a prolonged basis. So conceptualisation of poverty by people in the community referred to circumstances that were noticeable through measurable means strongly indicated by monetary difficulties. The data indicated that experiences of poverty could vary from mild to extreme and could be temporary or a drawn out and persistent condition. The most deprived are those people and clusters at the furthest end of abject penury.

"I have not eaten the whole day, I only drunk water because I don't have the means"FGD \#3

"I cooked one cassava tuber for my seven children to share for dinner and today, I do not have money to buy anything"- FGD \#4

"I will go to my friend to borrow food when she is back from the farm"- FGD \#1

Farming was the main commercial activity taking place within the communities. Generally, the poorest were subsistence farming on lands owned by others who employed them as wage labourers. The poorest people that did own any land usually had under an acre.

"I have a small land piece of one acre for my farming activities”- FGD \#9.

“The plantain farm is on someone's small land and I am paid as a labourer"- FGD $\# 5$. 


\section{Employment}

The type of employment was important in determining the affordability of NHIS for an individual. Both key informants and focus group participants narrated that the poorest were generally jobless or engaged in a job or labour that generated low wages, such as a farm labourer. A further theme was that poverty was designated a seasonal occurrence worsened by the changeability of the weather. For example, a respondent stated:

"We're better off during the farming season and draw back into poverty when the season is over. Although, we're currently in the farming season, yields are low, but for us in this community, poverty is a cycle." (K1).

In contrast, rich people in Ghana were owners of businesses, cash crop farmers and government employees and had no economic obstacles to access both private insurance and NHIS:

"I own all these poultry farms and is worth over 2 million Ghana cedis"- FGD\# 2

"I work as a banker and pays for NHIS without any problem"- FGD \#4

Employment type was deemed a key source of income for the more affluent in Ghana and was influenced by education. Having wealth, an income and education, all influenced children's health and ability to pay NHIS:

"I am a teacher and have paid the insurance for myself and children"- FGD \# 7

"I pay for private insurance for my household as a lecturer because I am able to afford it for my family" FGD \#6.

\section{Education}

The capacity to pay for the highest education level for children, along with access to education materials and the type of school a child attended, were all reported to be indicators of household affluence. Key informants and focus group participants discussed how the poorest households in general lacked the ability to fund education of their children beyond the basic stage. Children who normally attended community day schools were from the worse off families compared to the more affluent who took their children to private schools. Some respondents pointed out that parents experiencing significant poverty frequently did not allow their children to attend any approved school, but instead children assisted parents in their activities like trading and farming. In these instances, trading was seen to generate rapid money compared to schooling:

"It takes long for a child to finish school and work for money" (FGD \#1) 
"I am showing my children how to trade so they can take over from me..... it's better to do it now while they are young" (FGD \#3).

Some key informants also noted that

"When some children finish school and can't quite get a job, they end up engaging in petty trading” (K2)

"I couldn't pay for his school fees so he dropped out after basic education, I am small scale farmer and do not have support from anyone. He sometimes help in the farm so as to get something to eat. Sometimes we don't even eat 3 three times a day because they are no money. We eat once and drink water in the evening. "' (K4).

\section{Assets}

The most deprived were described as only having a partial or complete lack of what could be considered usual possessions in a household. For example, some households only had a mat; some cookery equipment and a tiny radio, with the lodgings of some of the poorest constructed of mud and covered with a straw roof and mostly for single occupancy. These dwellings generally had no separate toilet facilities with bathroom amenities shared with other family units.

\section{"I do toilet at the bush"-(K7)}

(The interviewer, "Why?")

$\mathrm{K} 7$ "Because there's no toilet facilities. The one closer to us is 5 miles from this village and you have to pay one (1GHS) cedi's to toilet".

Poverty was also associated with a lack of material assets and food insecurity.

"I want to do farming but I do not have a piece of land"- FGD \#8

“haha, I don't have even one livestock, look, all I have is my mat and cooking utensils and I have packed them inside my clay house. These livestock are for my boss who is very rich, He has four by four car as well”- FGD \#5 


\section{Social marginalisation}

Themes from data highlight that the poor are socially marginalized in decision-making processes within their families, and more broadly in the implementation of the NHIS. The poorest people, according to both key informants and focus group participants, were normally excluded from community and family level discussions in decision making processes. Respondents explained that when relatives come together during bereavement and on other collective special events, the poorest can be marginalized. At such assemblies, relatives give money but because the poorest are not able to donate money, ideas emanating from them are disregarded and concerns commonly remained unaddressed as recounted by this respondent:

"My senior sister said our uncle died last week because he couldn't pay for the hospital fees for the surgery and when the family met yesterday to discuss the funeral I was not even invited because I do not have money to contribute towards the funeral"'- FGD \#7.

This type of marginalization (family level) extends to marginalization in relation to the NHIS and affects self-determination and freedom. This can have adverse effects for individuals and communities alike. According to a key informant "No one cares about the welfare of the community" (K9). Some of focus group participants felt disappointed and excluded in the decision to impose capitation on them:

"I'm very disappointed that we have never been involved in the NHIS decision making (FGD \#7).

I feel so disappointed that they did not tell us before the increase of the NHIS charges" (FGD \#9)

\section{Discussion}

Previous research outcomes in Ghana highlight the contextual and social features of poverty (2, 3). According to Sen (6) "poverty is not just a matter of being relatively poorer than others in the society but of not having some basic opportunities of social and material wellbeing -the failure to have certain minimum capabilities". The findings and implications of our research are of importance as they highlight a poor fit with official measures and the neglect of lay perspectives. 


\section{Poor fit with official measures}

According to the findings, which emphasise multiple aspects of poverty, the official criteria for identifying the poor in Ghana seem not to match the pro-poor policy rhetoric. Aryeetey et al. (2) noted that the criteria have failed to identify the core poor that the policy sought to exempt and only about $2 \%$ of the poor are exempted from paying the NHIS premium. Our findings noted similar features as the well-defined factors of poverty reported by study communities were not the same as the official measures used as criteria for exemptions under the Nationwide NHIS Act in Statutory or Legislative Instrument (LI-1809). The official method used to classify the poor under NHIS is based on the LI-1809. It emphasizes the criteria for a person to be exempted from paying NHIS charges includes a person with no noticeable income source or being classified as unemployed, a person with no permanent dwelling place, and a person not staying with an individual who has a job and in secure dwelling of abode (14). The FGDs and key informant interviews present a different perspective to inform policy makers in Ghana that the current official criteria for classifying the core poor are not appropriate. From the findings, the poorest who were engaged largely in small scale farming, earned least. Poor families could not even support the basic needs like food, water and clothing from their employment and thus were finding it difficult to pay for NHIS. In contrast, the more affluent were likely to support their children in education and to acquire material assets. Education was another factor linked to knowledge and motivation to become a member of the NHIS. The poor, however, were unlikely to educate either their children or themselves. This finding suggests that outreach efforts to increase knowledge about NHIS were usually insensitive and may lack relevance to many poor people with no formal education.

The study findings also suggest that LI-1809 criteria do not identify the indigents in Ghana effectively. Focus group participants and key informants noted that very few people meet the requirements of the exemption criteria when the L1-1809 is applied strictly and that many are not enrolled because of the difficulties in paying the non-SSNIT contribution, premium and out-of-pocket registration charges.

\section{The neglect of lay perspectives}

Both focus group participants and key informants noted the marginalization and social exclusion experienced in decision-making processes within the community. According to 
Exworthy et al. (28), in policy development, it is important to involve communities and take into account their opinions of issues and viewpoints to inform the policy process. This requires distinctive community approaches directed at gathering the opinion of those affected by a policy (28). In this study, lay perspectives were crucial in obtaining a comprehensive picture of poverty within the context of community life. Interestingly, a number of respondents suggested that the concerns of the poorest were not taken seriously taken or were disregarded and the NHIS does not listen to their perspective as it is other community or family meetings. The findings point to one of the paradoxes of poverty that the poorest in communities have the greatest need for social assistance in the NHIS, yet are more likely to be ignored because they have become the voiceless.

\section{Limitation}

This study is a single case study covering two regions of Ghana, Ashanti and Greater Accra. Further studies can ascertain a national picture of all the ten regions, which reflect differences in geographic, economic, socio cultural and lifestyle indicators in Ghana. As data saturation was not reached due to limited financial resources of the researcher and a small sample size, the results must be viewed with caution. Despite in depth discussions in focus groups and interviews, respondents may have been timid of voicing alternative views to the researcher, resulting in the prominence of socially desirable perspectives. In spite of these limitations, this qualitative study offers some broader perspectives on the link between poverty and NHIS coverage and could provide the basis of a broader study of the subject.

\section{Conclusions and policy implications}

A number of key issues emerged from this study. First, the features of poverty identified through the study showed the need for a multidimensional approach when dealing with poverty in exemptions of pro-poor policies like the NHIS. The depth of understandings presented in this paper complements more quantitative methodologies. Second, the findings from this community qualitative exercise highlight that communities should be the principal stakeholders in describing their disadvantage. Furthermore, schemes to help the poorest are more likely to succeed if the poor are included in the construction and implementation processes, as in the case of premium exemptions within the NHIS. Long-term investment in lay perspectives by involving the poorest within communities can build capacity in marginalized areas and enhance the skills and experiences of those experiencing deprivation. Having true participation from members of the target population can help the NHIS 
implementers to engage with high-risk poor populations. The study is thus proposing that to identify eligibility for exemptions, reliance only on income and quantitative measures is not enough and qualitative and community indicators can support identification processes. Finally, the findings have implications regarding future research. More research is needed to explore the burden of health service payments to determine whether they are the causes of poverty, especially for the socially vulnerable groups and to look more generally at how to deliver effective welfare systems to disadvantaged individuals and families in Ghana.

\section{Acknowledgements}

The research was conducted as part of a doctoral study at Leeds Beckett University. The authors would like to thank Professor Rachael Dixey who was the Director of Studies until 2016 and contributed to the study design and analysis.

\section{References}

1. Duclos, J.Y and Araar, A. Poverty and equity: measurement, policy and estimation with DAD.Springer Science and Business Media. 2007(2).

2. Aryeetey GC,Jehu-Appiah C,Spaan E, Agyepong I, Baltussen R. Costs, equity, efficiency and feasibility of identifying the poor in Ghana's National Health Insurance Scheme: empirical analysis of various strategies. Tropical Medicine \& International Health. (2012).17:43-51.

3. Akazili J, Welaga P, Bawah A, Achana FS, Oduro A, Awoonor-Williams JK, et al . Is Ghana's pro-poor health insurance scheme really for the poor? Evidence from Northern Ghana. BMC Health Services Research (2014). 14:637.

4. UNESCO, Learning to live together. http://www.unesco.org/new/en/social-andhuman-sciences/themes/internation (2017).

5. Alkire, S. and Santos, M.E.,Acute multidimensional poverty: A new index for developing countries. United Nations Development Programme -office background paper, (2010)

6. Sen A. The idea of justice. London: Allen Lane/Penguin. (2009).

7. Barimah K, Mensah J. Ghana's National Health Insurance Scheme: insights from members, administrators and health care providers. J Health Care (2013) 24:1378-90.

8. Ghana Statistical Service. Ghana Living Standards Survey: Report of the sixth Round (GLSS 6). Accra, Ghana. (2014). 
9. Bawumia M, The state of the economy: a foundation of concrete or straw? Accra Ghana(2016).

10. United Nation Development Program and Government of Ghana , Report on \#Millennium Development Goals (2010) (internet) http://www.gh.undp.org/content/dam/ghana/docs/Doc/Inclgro/UNDP_GH_IG_2010 MDGreport_18102013.pdf. Date accessed 12/3/2018.

11. Ghana Statistical Service. Key Statistics: Key Social, Economic, and Demographic Indicators.GSS, Office of the President, Accra, Ghana (2013) http://www.statsghana.gov.gh Accessed June 1, 2017

12. National Health Insurance Scheme. Annual Report; National Health Insurance Regulations, L.I. 1809 (2004).

13. Witter S, Garshong B, Ridde V. An exploratory study of the policy process and early implementation of the free NHIS coverage for pregnant women in Ghana. International Journal for Equity in Health. (2013) 12.

14. National Health Insurance Regulation (LI 1809) Accra: Ghana Publishing Company Limited. (2004).

15. Van Parijs, Rethinking poverty in the developed world, 5th European Public Policy Conference (2013) http://eppc2013.wordpress.com/2013/04/19/philippe-van-parijsthe-euro-dividend Accessed July 7, 2017

16. Wamalwa, E.W., Implementation challenges of free maternity services policy in Kenya: the health workers' perspective. Pan African Medical Journal, (2015)22:1.

17. Elbers C, Fuji T, Lanjouw P, Ozler B and Yin W. Poverty alleviation through geographic targeting: how much does disaggregation help? Journal of Development Economics (2007) 83,198-213.

18. Hargreaves J, Morison AL, Gear JSS et al. Assessing household wealth in health studies in developing countries: a comparison of participatory wealth ranking and survey Burkina Faso: a community-based targeting approach to exempt the indigent from user fees. BMC Public Health (2007) 10, 631.

19. Aboagye, D. The National Health Insurance Scheme in Ghana: Policy, Equity, Community and Healthcare. PhD Thesis, Leeds Beckett University. (2016).

20. Denzin, N.K. and Lincoln, Y.S. eds., The Sage handbook of qualitative research. Sage (2011).

21. Chakravarti, D., Voices unheard: the psychology of consumption in poverty and development. Journal of Consumer Psychology, (2006).16(4), pp.363-376. 
22. Minkler, M., Ethical challenges for the "outside" researcher in community-based participatory research. Health Education \& Behaviour, (2004).31: 6, pp.684-697.

23. Coyne, I.T., Sampling in qualitative research. Purposeful and theoretical sampling; merging or clear boundaries? Journal of advanced nursing, (1997). 26: 3, pp.623-63.

24. Attride-Stirling, J. Thematic networks: an analytic tool for qualitative research. Qualitative Research (2001) 1:3, 385-405.

25. Boyatzis, R.E., Thematic analysis and code development: Transforming qualitative information. London and New Delhi: Sage Publications. (1998).

26. Bernard, H.R.,Wutich, A.and Ryan, G.W., Analysing qualitative data: Systematic approaches. SAGE publications (2016).

27. Ryan, G.W. and Bernard, H.R., Techniques to identify themes. Field methods,2003. 15(1), pp.85-109.

28. Exworthy, M., Berney L, and Powell M "How Great Expectations In Westminster May Be Dashed Locally": The Local Implementation of National Policy on Health Inequalities. Policy and Politics (2002) 30 (1):79-96.

\section{Author Biographies}

Da Costa Aboagye is a research and academic practitioner at the University of West London in the United Kingdom. He specializes in Health Promotion (Health and Well-being) and Public Health with special interests in National or Social Health Insurance Schemes Finance, Universal Health Coverage, Global Health, Health Impacts Assessment, Sustainable Development, Equity, Human Rights, Social Determinants, Social Protection, Politics, Poverty, Community, and Health care. He is the lead for the Ghana Government project of establishing a Health Promotion Division in Ghana to champion the Health Promotion needs of Ghana and globally. "Implementation plan for health promotion division in Ghana"Working paper submitted on December 4, 2017.

Jane South is a professor of Healthy Communities working in the field of volunteering, active citizenship, and community health. Jane has a national and international reputation for her research on lay health workers and volunteer roles in health. She has a long standing interest in community engagement and is currently on secondment to Public Health England 
as an expert advisor on community-centered approaches for health and well-being. From 2006 to 2013, Jane was Director of the Centre for Health Promotion Research at our University where she built up an extensive portfolio of research, publications, and public engagement activity.

Hafiz T. A. Khan is a Professor of Public Health and Statistics at University of West London, UK. He is also an associate research fellow at the Oxford Institute of Population Ageing, University of Oxford, UK. He trained as health statistician and developed his academic career in the area of public health over the last 25 years. His current research interests include healthy aging, comorbidity in later life, long-term care, and support provisions for elderly. He has published important articles in health- and population-related issues. He has co-authored two books Research Methods for Business and Social Science, Sage, 2007 and 2014. 